\title{
Erratum to: Is capsulectomy a feasible and useful measure in internal pulse generator replacement procedures? A technical note on the use of the PEAK PlasmaBlade ${ }^{T M}$
}

Domenico Servello $^{1}$ Alberto R. Bona ${ }^{1,2} \cdot$ Edvin Zekaj $^{1}$

Published online: 7 April 2017

(C) Springer-Verlag Wien 2017

Erratum to: Acta Neurochir (2016) 158:1165-1168

DOI 10.1007/s00701-016-2793-5

The affiliations of all authors have been corrected in this article.

The online version of the original article can be found at http://dx.doi:10.1007 /s00701-016-2793-5

$\triangle$ Alberto R. Bona

alberto.bona@hotmail.com

1 Neurosurgery Department, Galeazzi Research and Clinical Hospital, Milan, Italy

2 University of Milan, Milan, Italy 